\title{
Study of Pregnancy with COVID-19 and its Clinical Outcomes in a Tertiary Care Teaching Hospital in Western India
}

\author{
Shital N Kapadia ${ }^{1}$, Amiya Mehta ${ }^{2}$, Charul R Mehta ${ }^{3}$, Sumeeta T Soni ${ }^{4}$, Neelam Joharwal ${ }^{5}$, Monica Dixit ${ }^{6}$, Jolly G Vaishnav ${ }^{7}$
}

\begin{abstract}
Objectives: To study cases of pregnancy with coronavirus disease-2019 (COVID-19) and its clinical outcome. To study evidence of the vertical transmission in pregnant women infected with COVID-19.

Materials and methods: A prospective study was performed in BJ Medical College and Civil Hospital, Ahmedabad, one of the biggest designated (1200 beds) COVID hospitals in India. It was carried out from June 2020 to mid-October 2020. A total of 50 pregnant patients who were COVID19 positive and admitted to the labor room were studied.

Results: The mean age of the mothers was $27.40 \pm 4.76$ years (range: 19-36 years) and mean gravidity was $1.67 \pm 1.41$ (range: 1-4). The mean gestational age was $38.31 \pm 1.67$ weeks. The main complaint was fever in $22(44 \%)$, followed by dry cough in $9(18 \%)$, sore throat in $4(8 \%)$, headache in $2(4 \%)$, malaise in 7 (14\%), and diarrhea in $2(4 \%)$ patients. Twenty-two (44\%) patients showed an elevated C-reactive protein level, $17(34 \%)$ had lymphopenia, $19(38 \%)$ had mild elevation of the D-dimer level, and $16 \%$ of the patients had increased interleukin 6 levels. Most of the patients had normal renal function test (RFT) and liver function test (LFT) results. A majority of them (86\%) had normal chest X-ray, whereas rest of them (14\%) had haziness in bilateral lung fields. Twenty-six (52\%) patients underwent C-section, and 23 (46\%) delivered vaginally. Four (8\%) babies required the admission in the newborn intensive care unit for mild birth asphyxia but were discharged well. Five babies developed physiological jaundice and required single surface phototherapy (SSPT). Forty-eight (96\%) out of 50 had negative vaginal swab by reverse transcription polymerase chain reaction (RT-PCR), 48 (96\%) did not show any evidence of the virus in the expressed breast milk by RT-PCR. We collected the cord blood sample of 35 patients after delivery which was found to be negative in all (100\%). The nasopharyngeal swab of all the babies was negative on the very first day. Day 7 repeat swab was found positive only in one baby. This transmission was mostly via respiratory droplets during intermittent assisted breastfeeding. Most of the cases were having mild disease without acute respiratory distress syndrome (ARDS), which responded to the supportive treatment. Four patients ( $8 \%$ ) had severe anemia and required blood transfusion.

Conclusion: Most of the cases were having mild disease without ARDS, which responded to supportive treatment. Reassuringly, there was no evidence of poor fetal outcome, intrauterine fetal deaths, or premature deliveries. We did not find any evidence of the virus in the vaginal fluid, cord blood, or breast milk supporting vertical transmission of COVID-19 in the third trimester of pregnancy, even if patient delivered vaginally. Keywords: Pregnancy with COVID-19, Vertical transmission.

Journal of South Asian Federation of Obstetrics and Gynaecology (2021): 10.5005/jp-journals-10006-1886
\end{abstract}

\section{INTRODUCTION}

The coronavirus disease 2019 (COVID-19), caused by severe acute respiratory syndrome coronavirus 2 (SARS-CoV-2), is a global pandemic now. Since the first case of COVID-19 pneumonia was reported in Wuhan, Hubei Province, China, in December 2019, the infection has been rapidly spreading to the rest of China and other countries of the world. ${ }^{1-3}$ The first case of COVID-19 in India was reported in the month of January 2020, in the southern region, and in March 11, 2020, COVID-19 was announced as a pandemic by the World Health Organization (WHO). ${ }^{4}$ Globally since 18 October 2020 , there have been $39,596,858$ confirmed cases of COVID-19, including 1,107,374 deaths, reported to the WHO. In India, from January 2020 to 18 October 2020, there have been 7,494,551 confirmed cases of COVID-19 with 114,031 deaths (WHO). Many epidemiological studies stated that COVID-19 was a potential threat to people of any age and severity associated was proportionately related to age and comorbidities. ${ }^{5}$

Pregnancy predisposes to immunological adaptations to withstand the fetal semiallograft, and this state of the suppressed T-cell activity makes pregnant women vulnerable to viral infections including COVID-19, and in addition to this, various respiratory and circulatory physiological changes occurring during pregnancy further makes them liable to catch viral infections during pregnancy. Studies during the $2009 \mathrm{H} 1 \mathrm{~N} 1$ influenza pandemic concluded that
1,2,5,6 Department of Obstetrics and Gynecology, BJ Medical College and Civil Hospital, Ahmedabad, Gujarat, India

3,7Department of Paediatrics, BJ Medical College and Civil Hospital, Ahmedabad, Gujarat, India

${ }^{4}$ Department of Microbiology, BJ Medical College and Civil Hospital, Ahmedabad, Gujarat, India

Corresponding Author: Shital N Kapadia, Department of Obstetrics and Gynecology, BJ Medical College and Civil Hospital, Ahmedabad, Gujarat, India, e-mail: sheetalobgy@gmail.com

How to cite this article: Kapadia SN, Mehta A, Mehta CR, et al. Study of Pregnancy with COVID-19 and its Clinical Outcomes in a Tertiary Care Teaching Hospital in Western India. J South Asian Feder Obst Gynae 2021;13(2):125-130.

Source of support: Dr. Pranay Shah, Professor, Head of the Department, Microbiology and Dean, BJ Medical College for his heartfelt support extended to us for conducting this study.

Conflict of interest: None

pregnancy with $\mathrm{H} 1 \mathrm{~N} 1$ is a high-risk condition which carries higher risk of severe pneumonia, acute respiratory distress syndrome (ARDS), mechanical ventilation, and death when compared with

(0) Jaypee Brothers Medical Publishers. 2021 Open Access This article is distributed under the terms of the Creative Commons Attribution 4.0 International License (https://creativecommons.org/licenses/by-nc/4.0/), which permits unrestricted use, distribution, and non-commercial reproduction in any medium, provided you give appropriate credit to the original author(s) and the source, provide a link to the Creative Commons license, and indicate if changes were made. The Creative Commons Public Domain Dedication waiver (http://creativecommons.org/publicdomain/zero/1.0/) applies to the data made available in this article, unless otherwise stated. 
reproductive-aged nonpregnant women. This was in accordance with few studies on the severe acute respiratory syndrome (SARS) and Middle East respiratory syndrome (MERS) epidemics, where pregnant patients were more likely to develop organ dysfunction and die. ${ }^{6}$

A great challenge posed by the recent outbreak of COVID-19 on the part of obstetricians is how to manage pregnancy with COVID-19. It is the early phase of the epidemic, and even till date, only limited data are available on the effect of COVID-19 on pregnant women. The risk of intrauterine and peripartum transmission of the virus to the fetus is also largely unknown. Until now, most of the guidelines are derived from previous experiences with other highly pathogenic coronaviruses, namely SARS and MERS.

$A$ recent consensus stated that there is no clear evidence on timing of optimal delivery, safety of vaginal delivery, or whether cesarean delivery prevents vertical transmission at the time of delivery. Lately, some case reports and clinical series have been published on the course of pregnancy with COVID-19 and fetomaternal outcomes. Although a very limited number of the studies have been published regarding vertical transmission and that too with a small sample size. Few of the studies have shown that vertical transmission is unlikely, ${ }^{6-9}$ but our primary data analysis (March 2020 to May 2020) showed that 7 out of 29 babies delivered at Civil Hospital Ahmedabad (CHA) were positive for COVID-19 RT-PCR in the first 48 hours of delivery by nasopharyngeal swab. So, this study was designed to study cases of pregnancy with COVID-19 and its clinical outcome.

\section{Materials and Methods}

\section{Study Design and Patient Selection}

This was a prospective study performed in BJ Medical College and Civil Hospital, Ahmedabad, one of the biggest designated COVID hospitals (1200 bed) in India for pregnant women with COVID-19.

A prospective study was designed to study cases of pregnancy with COVID-19, its outcome, and evidence of vertical transmission in pregnant woman infected with COVID-19.

The study was aimed to know the clinical outcome of mothers infected with COVID-19, baby outcomes of these mothers, and evidence of potential for vertical transmission. It was carried out from June 2020 to mid-October 2020. This study was reviewed and approved by the Institutional Ethics Committee. All participants were counseled regarding the study design, its objectives, methodology, and implication of the study, and verbal and written informed consents were taken from participants.

Patients with following inclusion criteria were enrolled in the study:

- All antenatal patients who were COVID-19 positive (RT-PCRnasopharyngeal swab) and in the late third trimester admitted to the labor room of the COVID hospital, Civil Hospital, Ahmedabad, and willing to participate in the study.

- All women who delivered outside the civil hospital and approaching the civil hospital within 24 hours of delivery.

- All babies who were delivered by the above-mentioned mothers.

Following mothers were excluded from study:

- Antenatal patients approaching to the labor room with already intrauterine fetal deaths.

- Antenatal mothers who were not willing to participate in the study.

- Antenatal patients who were coming with early pregnancy.
- Suspected patients who later on turned out to be COVID-19 negative.

- Patients who were given antiviral therapy before the delivery of the baby.

We investigated all the patients. They were followed and course of disease, course of labor, mode of delivery, baby outcome (baby weight, maturity, Apgar score, need for the newborn intensive care unit [NICU] care, baby's COVID-19 status), postnatal complications, comorbidities, or other obstetrics complications were noted. On admission, the nasopharyngeal swab of patients was taken and sent for RT-PCR. Once they went in, a spontaneous or induced labor vaginal swab was taken and sent for RT-PCR. After delivery, the cord blood was collected and sent for RT-PCR. We have used kits approved by the Indian Council of Medical Research as well as methods for testing the result of positive, negative, and indeterminate. The breastfeeding policy was as follows: (1) Kangaroo care and a continuous skin-to-skin contact of the baby with the mother was avoided. (2) Neonatal samples were taken preferably before the first feed or latest within 24 hours of birth. (3) Breastfeeding was allowed with partial separation. All mothers were taught the use of N-95 mask, handwashing, handling of the baby, and cleaning of the breast with saline. Babies were kept in strict isolation till the samples were taken and thereafter handed over to the family for assisted intermittent breastfeeding. Once the breast milk secretion was established, breast milk swabs were taken from all the mothers and sent for RT-PCR. Nasopharyngeal swabs of all babies were taken on Day 7 again and sent for RT-PCR. Chest X-ray of all patients was taken after delivery.

\section{Outcomes}

The outcomes of interest included the following: course of disease, course of labor, mode of delivery, baby outcome (baby weight, maturity, Apgar score, need for NICU care, baby's COVID-19 status), postnatal complications, comorbidities, or other obstetrics complications and potential for vertical transmission by various investigations carried out.

\section{Statistical Analysis}

Data were collected and analyzed. Continuous variables were described as either means and standard deviations or medians and interquartile ranges (IQRs), as appropriate. Categorical variables were described as frequencies and percentages.

\section{Results}

We have studied 50 COVID-positive (RT-PCR) mothers in the third trimester, who were admitted in the COVID labor room in accordance with the inclusion-exclusion criteria.

Table 1 provides demographic details of patients. The mean age of the mothers was $27.40 \pm 4.76$ years (range 19-36 years), and the mean gravidity was $1.67 \pm 1.41$ (range 1-4). The mean gestational age was $38.31 \pm 1.67$ weeks.

Table 2 describes presenting complaints of the patients. On admission, the main complaint was fever in 22 (44\%), followed by dry cough in $9(18 \%)$, sore throat in $4(8 \%)$, headache in $2(4 \%)$, malaise in $7(14 \%)$, and diarrhea in $2(4 \%)$ patients. Most of the patients had one or two spikes of low-grade fever $\left(37.5^{\circ} \mathrm{C}-38.7^{\circ} \mathrm{C}\right)$. Although few patients (18\%) were asymptomatic, they were found to be RT-PCR positive for COVID in the outside hospital and were referred to us for further management. One of the asymptomatic 
(on admission) patients had fever in the postpartum period, but she was also diagnosed with enteric fever. None of the patients required intensive care unit (ICU) admission.

Table 3 demonstrates various laboratory and radiological investigations. Twenty-two (44\%) patients showed an elevated CRP level, 17 (34\%) had lymphopenia, 19 (38\%) had mild elevation of the D-dimer level, and few of them (16\%) had increased IL- 6 levels. Most of them had a normal procalcitonin level. Most of the patients had normal renal and liver function tests. A majority (86\%) of them had normal chest X-ray, whereas rest of them (14\%) were having haziness in bilateral lung fields.

Table 4 indicates the mode of delivery. Half of the patients $(52 \%)$ required a cesarean section (CS) for obstetrics indications (five for fetal distress, five for cephalopelvic disproportion, five with the previous CS and refusal for the trial of labor after the CS, four for malpresentation, two for previous two CSs, two for postdate with induction failure, two for placenta previa, one for severe oligohydramnios), and the rest of the patients $(48 \%)$ delivered vaginally. Out of 24 patients who delivered normally, one required instrumental delivery. We found a higher operative delivery rate in this study group owing to obstetrics indications as described above and not because of COVID-19.

Table 5 describes the babies' outcome. The Apgar score was normal in $46(92 \%)$ babies. Only $4(8 \%)$ babies required NICU admission for mild birth asphyxia and were discharged well with a good outcome. One baby out of these four was transferred to pediatric surgery department as the baby was diagnosed with an imperforate anus. The baby was operated and discharged with colostomy. None of the babies from our study group developed severe birth asphyxia. Five babies (10\%) developed physiological jaundice and given SSPT in the maternity ward. Only one neonatal death was noted because of the respiratory disease syndrome-hyaline membrane disease-due to extreme prematurity in twin gestation. Day 1 nasopharyngeal swab was negative by RT-PCR in all babies of our study group. Day 7 repeat swab was found positive only in one baby. This transmission was mostly via respiratory droplets during intermittent assisted breastfeeding.

Table 1: Demographic factors

\begin{tabular}{lc}
\hline Factor & Mean $\pm S D$ \\
\hline Age & $27.40 \pm 4.76$ \\
Gravidity & $1.67 \pm 1.4$ \\
Period of gestation & $38.31 \pm 0.95$ \\
BMI & $25.28 \pm 1.99$ \\
\hline $\mathrm{BMI}=$, body mass index &
\end{tabular}

Table 2: Chief presenting complaints

\begin{tabular}{llll}
\hline S. No. & Chief complaints & $\begin{array}{l}\text { No. of patients having } \\
\text { this complaint }\end{array}$ & Percentage \\
\hline 1 & Fever & 22 & 44 \\
2 & Dry cough & 9 & 18 \\
3 & Sore throat & 4 & 8 \\
4 & Diarrhea & 2 & 4 \\
5 & Malaise & 7 & 14 \\
6 & Asymptomatic & 9 & 18 \\
7 & Headache & 2 & 4 \\
\hline
\end{tabular}

Table 6 described results of various investigations carried out to know the potential of vertical transmission. Forty-eight (96\%) out of fifty patients had negative vaginal swab by RT-PCR, and forty-eight (96\%) of them did not show any evidence of the virus in the expressed breast milk by RT-PCR. We collected the cord blood sample in all (35 patients) who delivered at our hospital which was found to be negative in all (100\%). Rest of them (15 patients) delivered outside the hospital and referred to our hospital for further management of COVID-19. The nasopharyngeal swab of all the babies was negative on the very first day. Day 7 repeat swab was found positive only in one baby. This transmission was mostly via respiratory droplets during intermittent assisted breastfeeding.

Table 7 has narrated associated obstetrical and medical complications. We could find that $9(18 \%)$ patients had crossed their expected date of delivery and 4 (8\%) patients presented with severe anemia and required blood transfusion.

Most of the cases were having mild disease without ARDS, which responded to supportive treatment. This is described in Table 8. None of the patients from our study group required ICU admission.

\section{Discussion}

In the present study, presenting clinical features were fever, dry cough, malaise, and diarrhea. Although few of the patients were asymptomatic, they were tested for COVID-19 as a part of planned preoperative workup outside our hospital and referred for further management as they turned out to be positive. Fever, dry cough, sore throat, muscle soreness, shortness of breath, and occasional diarrhea were the common presenting symptoms, ${ }^{10-12}$ as depicted in Fig. 1 representing chief presenting complaints. There was no significant difference

Table 3: Laboratory and radiological presentation

\begin{tabular}{llll}
\hline & & $\begin{array}{l}\text { Number of } \\
\text { patients }\end{array}$ & Percentage \\
\hline 1 & Elevated CRP & 22 & 44 \\
2 & Lymphopenia & 17 & 34 \\
3 & Elevated D-dimer & 19 & 38 \\
4 & Elevated IL-6 (mild) & 8 & 16 \\
5 & Elevated LDH & 6 & 12 \\
6 & Increased ferritin & 3 & 6 \\
7 & Altered RFT & 0 & 0 \\
8 & Altered LFT & 0 & 0 \\
9 & No. of patients having X-ray & 7 & 14 \\
& haziness in the lung fields & & \\
10 & No. of patients not having & 43 & 86 \\
& normal X-ray & &
\end{tabular}

$\mathrm{LDH}=$ Lactate dehydrogenase

Table 4: Mode of delivery

\begin{tabular}{llll}
\hline S. No. & Mode of delivery & Number of patients & Percentage \\
\hline 1 & Cesarean section & 26 & 52 \\
2 & Vaginal delivery & 23 & 46 \\
3 & Forceps delivery & 1 & 2 \\
\hline
\end{tabular}




\begin{tabular}{|c|c|c|c|}
\hline S. No. & Baby outcome & Number & Percentage \\
\hline 1 & $\begin{array}{l}\text { Swab positive by } \\
\text { RT-PCR (Day 1) }\end{array}$ & 0 & 0 \\
\hline 2 & $\begin{array}{l}\text { Swab positive by } \\
\text { RT-PCR (Day 7) }\end{array}$ & 1 & 2 \\
\hline 3 & $\begin{array}{l}\text { No NICU admission } \\
\text { required }\end{array}$ & 45 & 90 \\
\hline 4 & $\begin{array}{l}\text { Babies required } \\
\text { NICU admission but } \\
\text { discharged well }\end{array}$ & 4 & 8 \\
\hline 5 & Neonatal death & 1 & 2 \\
\hline 6 & Average baby weight & $02.66 \pm 00.58(2)$ & $\begin{array}{l}2660 \mathrm{gm} \\
(580-4000 \mathrm{gm})\end{array}$ \\
\hline 7 & Premature delivery & 1 & 2 \\
\hline
\end{tabular}

Table 6: Investigations to know the potential of vertical transmission

\begin{tabular}{llllc}
\hline Swab type & $\begin{array}{l}\text { Positive } \\
\text { number }\end{array}$ & $\begin{array}{l}\text { Percentage } \\
\text { (\%) }\end{array}$ & $\begin{array}{l}\text { Negative } \\
\text { number }\end{array}$ & $\begin{array}{l}\text { Percentage } \\
(\%)\end{array}$ \\
\hline $\begin{array}{l}\text { Mothers' vaginal } \\
\text { swab }\end{array}$ & 2 & 4 & 48 & 96 \\
$\begin{array}{l}\text { Mothers' expressed } \\
\text { breast milk }\end{array}$ & 2 & 4 & 48 & 96 \\
$\begin{array}{l}\text { Cord blood } \\
\begin{array}{l}\text { Babies' nasopharyn- } \\
\text { geal (Day 1) }\end{array}\end{array}$ & 0 & 0 & 35 & 100 \\
$\begin{array}{l}\text { Baby's nasopharyn- } \\
\text { geal (Day 7) }\end{array}$ & 1 & 2 & 50 & 100 \\
\hline
\end{tabular}

in symptoms between pregnant women and nonpregnant women. ${ }^{13}$ Our study also had similar findings, and we did not notice any severe symptoms or rapid deterioration of the existing symptoms.

Till March 2020, the COVID-19 outbreak was a newer disease for the whole world with limited evidence-based guidelines. It was a great challenge even for the obstetricians whether pregnant women would have similar outcomes compared with nonpregnant women of similar clinical profile with COVID-19 infection. Studies had found an higher association of severe symptoms, poorer clinical outcome, need for ICU admission, mechanical ventilation, organ dysfunction, and death as compared with the control group. ${ }^{14}$ In our study, we did not find such results, as also reported in a recently published case series. ${ }^{6}$ We would like to mention few of the studies having similar observations, i.e., Chen et al. derived the relationship between clinical characteristics among three pregnant women with confirmed COVID-19 infection and placental pathology. No trace of infection was found in the placenta or in the neonate. Moreover, there was neither any difference noticed in the course of disease between women in late pregnancy and nonpregnant patients nor any adverse fetomaternal outcome seen. ${ }^{15}$

In another study, evaluation of clinical records, laboratory investigations, and CT scan was carried out among nine women with confirmed COVID-19 infections in the Zhongnan Hospital of Wuhan University, Wuhan, China. The conclusion drawn stated no noticeable difference between the course of disease in infected pregnant women and nonpregnant patients. No evidence was found supporting vertical transmission of COVID-19 in late

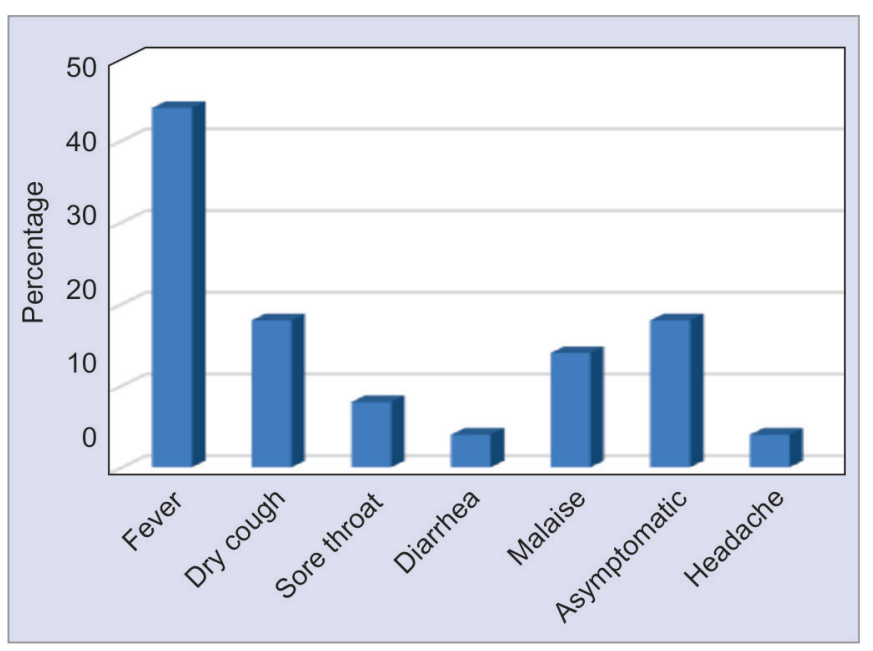

Fig. 1: Chief presenting complaints

Table 7: Various obstetric or medical complications among patients

\begin{tabular}{lllc}
\hline & & $\begin{array}{l}\text { No. of patients having } \\
\text { this complication }\end{array}$ & Percentage \\
\hline 1 & Anemia & 4 & 8 \\
2 & Preeclampsia & 3 & 6 \\
3 & Hypothyroidism & 1 & 2 \\
4 & Epilepsy & 1 & 2 \\
5 & Postdate & 9 & 18 \\
6 & Enteric fever & 1 & 2 \\
\hline
\end{tabular}

Table 8: Treatment given

\begin{tabular}{|c|c|c|c|}
\hline S. No. & Treatment given & $\begin{array}{l}\text { No. of } \\
\text { patients }\end{array}$ & Percentage \\
\hline 1 & Antibiotics & 46 & 92 \\
\hline 2 & Antipyretics & 22 & 44 \\
\hline 3 & $\mathrm{O}_{2}$ inhalation & 4 & 8 \\
\hline 4 & NRBM & 0 & 0 \\
\hline 5 & HFNC & 0 & 0 \\
\hline 6 & BIPAP & 0 & 0 \\
\hline 7 & Ventilator & 0 & 0 \\
\hline
\end{tabular}

NRBM $=$ Non Re-Breather Mask

HFNC $=$ High-Flow Nasal Cannula

BIPAP = Bilevel Positive Airway Pressure

pregnancy. Nine live births and no mortality were reported. Even no neonate tested positive. ${ }^{13}$ In a retrospective study conducted at the Hubei province including 16 women with COVID-19 infection in pregnancy and 45 pregnant women without COVID-19 undergoing C-section, the course of disease and neonatal outcome were studied. No remarkable difference was found in the cases of fetal distress, meconium-stained amniotic fluid, preterm delivery, and neonatal asphyxia. No trace of infection was found in neonates. ${ }^{16}$ These findings are comparable with a retrospective cohort study conducted in a tertiary referral hospital in southern India concluding that a majority of the women were asymptomatic 


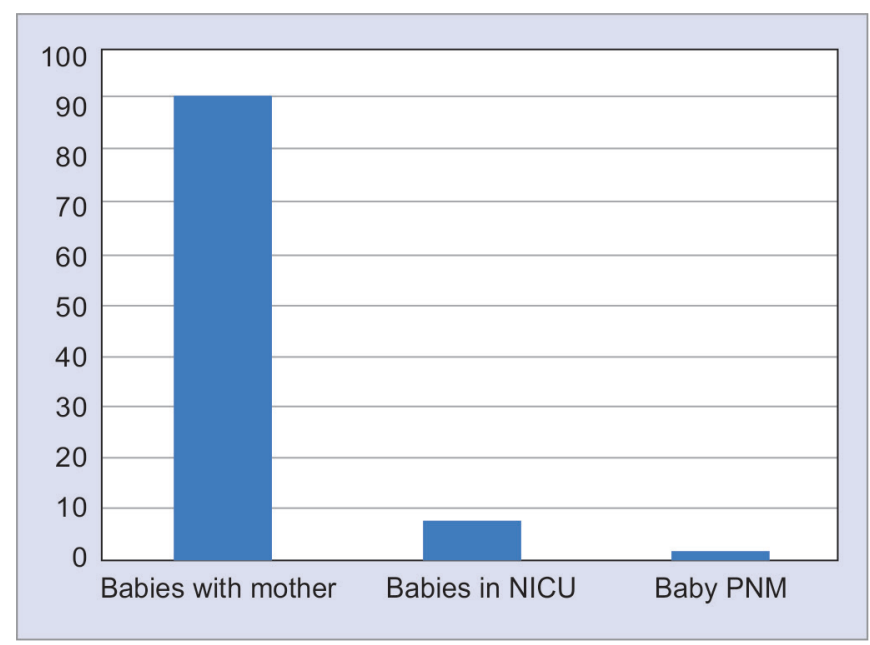

Fig. 2: Percentage of babies having NICU admission

at presentation diagnosed on routine testing. Mostly showing recovery within 8-14 days, even a positive neonate was breastfed, and all were asymptomatic. ${ }^{17}$

We studied the vaginal swab, cord blood sample, and expressed breast milk for evidence of the virus, supporting vertical transmission of COVID-19. The results are comparable with those of other studies. Neonatal outcomes in terms of NICU admission or mortality have been compared and stated in Fig. 2 (in the form of bar chart).

Jyan conducted a study including 116 cases of pregnancy with COVID-19. Very few (six patients) progressed to severe ARDS required ICU admission, whereas the rest recovered from mild pneumonitis. ${ }^{8}$ Juusela reported two cases of pregnancy with COVID-19 complicated by cardiomyopathy. ${ }^{18}$ A systematic review and meta-analysis published by Mascio reported poorer neonatal outcome in pregnancy with COVID-19. They also noted a higher rate of the CS in their study group. ${ }^{19}$ In our study group, only one patient had preterm labor. We found a higher operative delivery rate in this study group owing to obstetrics indications as described above, not because of COVID-19. Rashid et al. stated on the basis of two case reports that COVID-19 in the third trimester should be managed with utmost care especially if it is high risk pregnancy and associated with comorbidity. They should be taken care of in a tertiary care center ICU facilities prevail. Multidisciplinary approach toward management of pregnancy with COVID-19 and frequent and keen monitoring. ${ }^{20}$

\section{Conclusion}

This study had a substantial sample size of all the research on pregnancy with COVID-19 published till date. In our study, most of the cases were having mild disease without ARDS, which responded to supportive treatment. Reassuringly, there is no evidence of poor fetal outcome, intrauterine fetal deaths, or premature deliveries. We did not get any evidence of the virus in the breast milk, vaginal secretions, or cord blood or any nasopharyngeal swab of the baby was positive on birth supporting vertical transmission of COVID-19 in the third trimester of pregnancy, even if the patient delivered vaginally. Because the mothers can transmit the COVID-19 infection to their baby via respiratory droplets while breastfeeding, the mothers with known or suspected COVID-19 are advised to follow simple precautions such as physical distancing, wearing a mask, keeping rooms well ventilated, avoiding crowds, cleaning hands, and coughing into tissue during breastfeeding.

\section{References}

1. Huang C, Wang Y, Li X, et al. Clinical features of patients infected with 2019 novel coronavirus in Wuhan, China. Lancet 2020;395:497-506. DOI: 10.1016/S0140-6736(20)30183-5.

2. World Health Organization. Novel coronavirus-China. 2020. Available at: https://www.who.int/csr/don/12-january-2020-novel-coronaviruschina/en/. Accessed March 7, 2020.

3. Center for Systems Science and Engineering (CSSE) at Johns Hopkins University. COVID19 dashboard. 2020. Available at: https://www.arcgis.com/apps/opsdashboard/index.html\#/ bda7594740fd40299423467b48e9ecf6. Accessed March 24, 2020.

4. Cucinotta D, Vanelli M. WHO declares COVID-19 a pandemic. Acta Biomed 2020;91(1):157-160. DOI: 10.23750/abm.v91i1.9397.

5. Wu Z, McGoogan JM. Characteristics of and important lessons from the coronavirus disease 2019 outbreak in China: summary of a report of 72314 cases from the Chinese center for disease control and prevention. JAMA 2020;323(13):1239-1242. DOI: 10.1001/ jama.2020.2648.

6. Qiancheng $X$, Jian S, Lingling $P$, et al. Coronavirus disease 2019 in pregnancy. Int J Infect Dis 2020;95:376-383. DOI: 10.1016/j. ijid.2020.04.065.

7. Cao $\mathrm{D}$, Yin $\mathrm{H}$, Chen J, et al. Clinical analysis of ten pregnant women with COVID-19 in Wuhan, China: a retrospective study. Int J Infect Dis 2020;95:294-300. DOI: 10.1016/j.ijid.2020.04.047.

8. Yan J, Guo J, Fan C, et al. Coronavirus disease 2019 in pregnant women: a report based on 116 cases. Am J Obstet Gynecol 2020;223(1):111. e1-111.e14. DOI: 10.1016/j.ajog.2020.04.014.

9. Chen $Y$, Peng $H$, Wang $L$, et al. Infants born to mothers with a new coronavirus (COVID-19). Front Pediatr 2020;8:104. DOI: 10.3389/ fped.2020.00104.

10. Dawei $\mathrm{W}, \mathrm{Bo} \mathrm{H}$, Chang $\mathrm{H}$, et al. Clinical characteristics of 138 hospitalized patients with 2019 novel corona virus infected pneumonia in Wuhan, China. JAMA 2020;323(11):1061-1069. DOI: 10.1001/jama.2020.1585.

11. Chen N, Zhou M, Dong X, et al. Epidemiological and clinical characteristics of 99 cases of 2019 novel coronavirus pneumonia in Wuhan, China: a descriptive study. Lancet 2020;395(10223):507-513. DOI: 10.1016/S0140-6736(20)30211-7.

12. Brandon $\mathrm{H}$, Viksejens $M$. Clinical characteristics of covid-19 in China. N Engl J Med 2020;382(19):1860-1861. DOI: 10.1056/ NEJMc2005203.

13. Chen H, Guo J, Wang $C$, et al. Clinical characteristics and intrauterine vertical transmission potential of COVID-19 infection in nine pregnant women: a retrospective review of medical records. J Lancet 2020;395(10226):809-815. DOI: 10.1016/S01406736(20)30360-3.

14. Creanga AA, Johnson TF, Graitcer SB, et al. Severity of 2009 pandemic influenza $A(\mathrm{H} 1 \mathrm{~N} 1)$ virus infection in pregnant women. Obstet Gynecol 2010;115(4):717-726. DOI: 10.1097/AOG.0b013e 3181d57947.

15. Chen S, Huang B, Luo DJ, et al. [Pregnant women with new coronavirus infection: a clinical characteristics and placental pathological analysis of three cases]. Zhonghua Bing Li XueZaZhi. 2020;49:E005. DOI: 10.3760/cma.j.cn112151-20200225-00138.

16. Zhang $L$, Jiang $Y$, Wei $M$, et al. [Analysis of the pregnancy outcomes in pregnant women with COVID-19 in Hubei Province]. Zhonghua Fu Chan KeZaZhi. 2020;55:E009. DOI: 10.3760/cma.j.cn11214120200218-00111. 
17. Nambiar SS, Ajith S, Reshmi VP, et al. Assessing disease outcome in COVID-19 pregnancies in a tertiary referral center in South India: a single-center retrospective cohort study. J S Asian Federat Obstet Gynaecol 2020;2020:1822. DOI: 10.5005/jp-journals-10006-1822.

18. Juusela A, Nazir M, Gimovsky M. Two cases of coronavirus 2019related cardiomyopathy in pregnancy. Am J Obstet Gynecol 2020;2(2):100113. DOI: 10.1016/j.ajogmf.2020.100113.
19. Mascio DD, Khalil A, Saccone G, et al. Outcome of coronavirus spectrum infections (SARS, MERS, COVID-19) during pregnancy: a systematic review and meta-analysis. Am J Obstet Gynecol 2020;2(2):100107. DOI: 10.1016/j.ajogmf.2020.100107.

20. Rashid F, Shahnaz S, Sharmin R, et al. Pregnancy with COVID-19: Weal and Woe. J S Asian Federat Obstet Gynaecol 2020;2020:1798. DOI: 10.5005/jp-journals-10006-1798. 